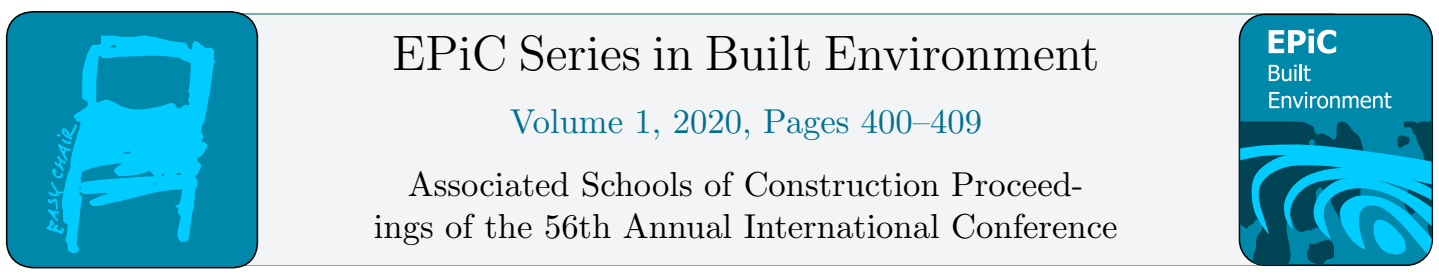

\title{
Supervisors' Reliance on Tacit Knowledge and Impediments to Knowledge Sharing in Trades
}

\author{
Priyansh Dogra $^{1^{*}}$ and Anthony E. Sparkling, Ph.D. ${ }^{1 \dagger}$ \\ ${ }^{1}$ Purdue University, West Lafayette, Indiana, U.S.A. \\ priyansh.dogra@live.com, asparkli@purdue.edu
}

\begin{abstract}
Construction field supervisors often exchange stories about how decisions they had made on previous projects have saved a substantial number of man-hours leading to improved profits. They rely on their experience-based knowledge to make day-to-day decisions in the field. The knowledge is mostly tacit in nature which is internalized over the course of experience and when asked, the supervisors are unable to codify or articulate it replicable in words. Many construction firms are incorporating knowledge management practices but still, the tacit dimension is relatively unexplored in the literature. Organizations are seeing the tacit dimension as a great competitive advantage due to its relative immobile nature. Employee retirements and knowledge loss are compelling construction firms to capture these know-hows to prepare the future workforce. The first step towards harnessing tacit knowledge is to identify it in practice. This study posits a tacit knowledge measure and identifies barriers to knowledge sharing through case studies involving specialty contactors. Findings show a clear relation between experience and tacit knowledge acquisition. Lack of time and formal procedures, and managers' reluctance to change are identified as the key barriers to knowledge sharing. Organizations can implement the proposed methodology framework and instrument to strengthen existing knowledge harnessing strategies.
\end{abstract}

\section{Introduction}

Unlike the manufacturing industry where decisions can be made by observing a sample product physically, the construction industry is completely disparate. It involves decision making about a product which is a conception or a virtual model or merely a combination of lines, arcs, and digits on a stack of drawings. The construction industry is characterized by its project-based nature where various teams work together for a common goal that generally disintegrates upon the completion of the project (Grover \& Froese, 2016) and oftentimes, it is known to deliver tangible products like

\footnotetext{
${ }^{*}$ Created the first draft and final stable version of this document.

${ }^{\dagger}$ Reviewed and verified the first draft of this document for final publication, suggested changes and additions.
} 
roads, buildings, bridges, etc. Today, it is widely recognized as a giant knowledge hub providing services to many stakeholders and requires more emphasis on knowledge capturing and sharing (Egbu \& Robinson, 2005). Baker et al. (1997) asserted that for effective knowledge solutions, there must be harmony among the three key elements: process, technology, and people. However, failing to acknowledge the human factor in the construction sector is one of the reasons for its underperformance (Pathirage, Amaratunga, \& Haigh, 2007).

Construction trade professionals are the individuals who get the things done by performing actual hands-on routine tasks at the Jobsite. Field supervisors act as an interface between management and trade professionals (Dowell \& Wexley, 1978) responsible for overseeing daily construction activities. Many supervisors attain their position in an organization based on expertise and technical know-how (MacNeil, 2004). Field supervisors have developed a plethora of knowledge through their experience that they have internalized and may find it difficult to communicate or decipher this knowledge in plain language (Skinnarland \& Yndesdal, 2014). Capturing knowledge in the construction industry is a challenging task as the knowledge is experience-based, the majority of which is tacit that makes it difficult to pass on to others (Kivrak, Arslan, Dikmen, \& Birgonul, 2008). Most of the knowledge management practices being employed deal with capturing explicit knowledge in the form of IT databases, documents, specifications, and so on but it lacks systems dealing with capturing tacit knowledge (Grover \& Froese, 2016). It is the tacit knowledge and not explicit which determines the competitiveness of a construction firm (Nesan, 2012). Tacit knowledge could play a vital role in the competitive market due to its relative immobility and unique nature as compared to explicit knowledge (Pathirage, et al., 2007), yet remains challenging to identify (USAID, 2013). Limited research has been done in the field assessing the degree to which individuals rely on tacit knowledge to perform a specific task (Chilton \& Bloodgood, 2008) and field supervisors often find it difficult to explain: how this tacit knowledge has been generated or implemented practically (Wilkinson, Sherratt, \& Farrell, 2015). Assessing the value of supervisors' experience-based tacit knowledge is necessary to plan beforehand effective strategies to capture it before they retire or leave the organization.

The knowledge loss due to potential mass exodus of retirees and workforce shortages are major factors that are compelling trade contractors to harness tacit knowledge of the experienced supervisors (Norberg-Johnson, 2019). To implement better strategies that can aid the contractor's decisionmaking in capturing and harnessing tacit knowledge, it is important to identify barriers that hinder knowledge sharing. Potentially useful knowledge can be captured in many ways like documents, videos, images, databases, and similar tools that could be used to train novices entering the industry to enhance their skillset. Therefore, our proposed methodology and measure in the study can be deployed by contractors at various intervals during the construction process to assess what type of knowledge field supervisors are using in decision-making or performing a particular construction task. Through this study, researchers intend to test the validity of the proposed measure by conducting semi-structured interviews with trade professionals and identifying barriers to knowledge sharing from the perspective of both managers and trade professionals/supervisors through a case study approach involving specialty contractors.

\section{Knowledge and its Dimensions}

Knowledge is one of the key factors behind human action. According to Albert Einstein, "Knowledge is experience. Everything else is just information". Knowledge is a concept like gravity which cannot be seen but its impacts can be perceived (Hunt, 2003). The western epistemology considers truthfulness as the main knowledge characteristic (Bolisani \& Bratianu, 2018) whereas for the eastern, knowledge is “justified true belief” (Nonaka \& Takeuchi, 1995). Various definitions have 
been coined by several authors albeit this word 'knowledge' remains fuzzy. The most relevant definition of knowledge for the study is "a set of personal capabilities, skills, information and experiences which an individual applies to solve a problem (Baker et al., 1997).

Polanyi (1966) classifies knowledge into two categories: tacit and explicit. Explicit knowledge can be easily codified either verbally or in written format. Organization's electronic and paper-based documents like contracts, specifications, online databases, manuals, etc. constitute explicit knowledge (Ahmad \& An, 2008). Tacit knowledge is based on an individual's experience which is hard to communicate and formalize. One can acquire tacit knowledge through observations, imitations, and practice (Teerajetgul \& Chareonngam, 2008) and it is beyond conscious awareness. These two dimensions of knowledge can also be viewed as the difference between "knowing that" and "knowing how" with regards to the work being performed (Wilkinson, Sherratt, \& Farrell, 2015). Most of the trade activities in a construction project rely on the technical know-how of the trade professionals and there is no 'beginner's luck' in this profession. An individual's work experience is a blend of both tacit and explicit knowledge. Generally, emerging individuals from trades who have gained much experience are promoted to higher positions like crew leaders or trade supervisors. Tacit knowledge is an amalgamation of experience and senses in the form of insights and intuition which is reflected in the form of decisions that field supervisors make in their everyday construction work. This knowledge gained over time becomes secondary in nature that one is not even aware of. For instance, an Electrical Field Supervisor laying out overhead feeder conduit racks may always try to find a common path to group feeder conduits to save on material and labor cost; or an Electrical Estimator who always instinctively finds opportunities to run the conduit underground to save on material and labor cost. Several epitomes are used to define tacit knowledge in the workplace like gut-feeling, rule-ofthumb, intuition, and so on.

\section{Previous Efforts: Gauging Tacit Knowledge and Barriers to Knowledge Sharing}

A significant amount of research has been conducted in the military and academia to identify and assess tacit knowledge; however, the construction sector is still lacking efforts to gauge it. Tacit Knowledge inventories for Military Leaders (TKML) are developed to identify and measure tacit knowledge and effectiveness of leadership among the military leaders (Hedlund, Horvath, Forsythe, Snook, \& Williams, 1998). Leonard and Insch (2010) developed a six-factor model and a measure of tacit knowledge in academia by incorporating three schemas of tacit knowledge: technical, cognitive, and social. The GPA was proposed as a final performance measure (Leonard \& Insch, 2010). Highlighting the construction industry, there is no specific performance measure like GPA (in academia), to identify the tacit knowledge of the field supervisors. A more reliable study by Chilton and Bloodgood (2008) implemented a scale to identify tacit knowledge in academia according to which tacit knowledge can be identified by measuring its constituent elements. This instrument was implemented in academia where the subjects were engaged in relatively explicit tasks, which is a limitation. Four elements of tacitness were used to develop the hypothesized model: Conscious Awareness, Expressibility, Demonstrability and Informal/Formal application; while using tacit knowledge, user is not much consciously aware of it; tacit knowledge is difficult to express or codify; tacit knowledge can be captured from demonstrations, hands-on experience and by imagining the final product; and while using tacit knowledge, the user does not apply formal systematic procedures (Chilton \& Bloodgood, 2008).

To implement efficient and effective knowledge capturing strategies, identification of the barriers preventing knowledge sharing plays a crucial role. A study by Sveiby (2007) highlights barriers to knowledge sharing at different levels in the organization. Lack of time, apathetic managers who are 
not walking the talk and silo mentality are identified as key barriers with respect to the workgroup, supervisor behavior and organizational contexts respectively (Sveiby, 2007). Lack of trust, lack of social networking, less awareness of self-knowledge, lack of training, poor organization culture, etc. are some of the other barriers to knowledge sharing identified through literature (Anwar, Rehman, Wang, \& Hashmani, 2019).

\section{Proposed Methodology and Framework}

\subsection{Assessing Field Supervisors’ Tacit Knowledge}

To assess the field supervisor's tacit knowledge, the measure developed by Chilton and Bloodgood (2008) is replicated. The aim is to implement a similar measure to verify its usefulness in the construction field. A few of the questions are modified, making them relevant to construction followed by their validation to remove ambiguities as per the feedback from two major specialty contractors from the mid-west US region. A methodology framework is developed for data collection (Figure 1). A snowball sampling technique is adopted, and the participants were identified through referrals. The proposed instrument is implemented parallelly with semi-structured interviews, which were conducted in two different construction projects with ongoing electrical works. Three electrical field supervisors with over 25 years of experience, one journeyman electrician with 10-15 years of experience and one apprentice electrician with less than 5 years of work experience were the participants. The journeyman and the apprentice were interviewed to validate the measure qualitatively by comparing their scores to those of the supervisors.

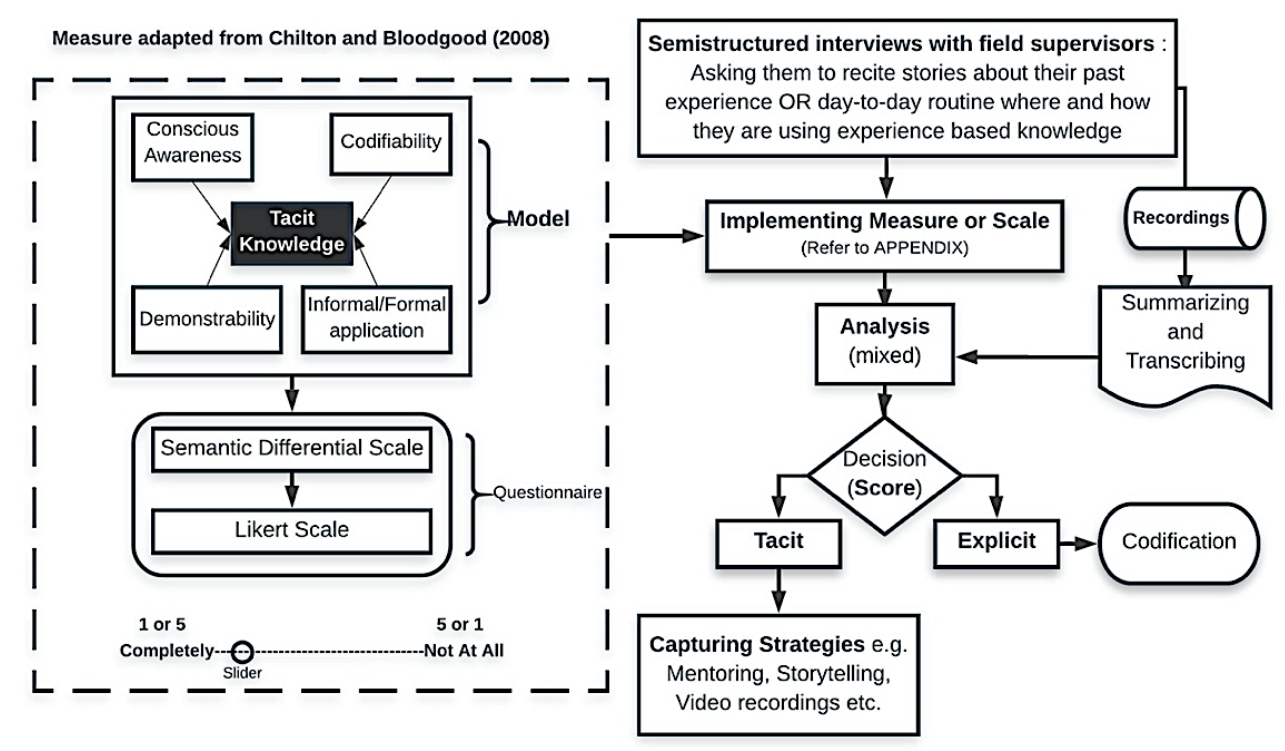

Figure 1: Proposed Methodology Framework

The measure deploys 26 questions based on the adapted model. Each question is represented as a semantic differential scale with "completely" and "not at all" as two extremities along with an 
electronic slider. Scores are assigned from 1 to 5 for some questions and 5 to 1 for others. A total score is calculated based on the position of the slider from all the questions. A score of 26 means complete reliance on explicit knowledge whereas a score of 130 implies complete reliance on tacit. The researchers believe that experienced field supervisors will have comparatively higher tacit knowledge scores than novice and less experienced apprentices when the proposed measure is implemented in the field. A mixed method of analysis will be used in the near future to validate the measure for further research. Audio recordings are used to create transcriptions to analyze the understanding of the instrument by comparing the responses obtained with the shared experiences.

\subsection{Barriers to Knowledge Sharing}

For this part of the study, an online survey questionnaire was developed based on the feedback from two of the major specialty contractors from the mid-west US region. Some of the identified barriers from the literature are used in the questionnaire (Table 1). The survey was distributed to approximately 300 electrical contractors associated with a major Electrical organization following a Simple Random Sampling (SRS) technique. The survey asks the participants to rank (in each class) the options in order of priority based on their experience. The different viewpoints of managers/executives towards knowledge sharing are also captured via free-text entry options that accompany each survey questionnaire. A total of 54 responses were obtained with a response rate of $18 \%$ which is considered appropriate given its length (Deutskens, Ruyter, Wetzels, \& Oosterveld, 2004). A similar survey was distributed among field-supervisors during semi-structured interviews and their responses were compared with those of executives/managers to find out the congruence in opinions.

\begin{tabular}{|c|c|c|}
\hline Group of Workers Context & $\begin{array}{l}\text { Supervisor/Managers } \\
\text { Behavior Context }\end{array}$ & Organizational Context \\
\hline $\begin{array}{l}\text { A. There is not enough time } \\
\text { available to share knowledge }\end{array}$ & $\begin{array}{l}\text { A. Lack of } \\
\text { encouragement from the } \\
\text { management }\end{array}$ & $\begin{array}{l}\text { A. Managers are reluctant to share } \\
\text { knowledge with employees }\end{array}$ \\
\hline $\begin{array}{l}\text { B. There are no formal } \\
\text { processes to share knowledge }\end{array}$ & $\begin{array}{l}\text { B. Managers are resistant } \\
\text { to change }\end{array}$ & $\begin{array}{l}\text { B. Top-level execution is apathetic } \\
\text { towards the workers }\end{array}$ \\
\hline $\begin{array}{l}\text { C. Sharing happens only when } \\
\text { the workers work together in an } \\
\text { activity }\end{array}$ & $\begin{array}{l}\text { C. Managers are } \\
\text { unwilling to take risk }\end{array}$ & $\begin{array}{l}\text { C. No formal process for sharing } \\
\text { knowledge }\end{array}$ \\
\hline $\begin{array}{l}\text { D. Some think that knowledge } \\
\text { is power and can be used to get } \\
\text { a promotion }\end{array}$ & $\begin{array}{l}\text { D. Managers not walking } \\
\text { the talk }\end{array}$ & $\begin{array}{l}\text { D. Retirees disappear with the } \\
\text { knowledge which they acquired by } \\
\text { experience }\end{array}$ \\
\hline \multirow[t]{2}{*}{$\begin{array}{l}\text { E. Workers are poorly informed } \\
\text { regarding knowledge sharing }\end{array}$} & $\begin{array}{l}\text { E. Managers and staff are } \\
\text { treated differently }\end{array}$ & E. Experience is not valued \\
\hline & & F. Stringent policies and procedure \\
\hline
\end{tabular}

Table 1: Barriers to Knowledge sharing in an organization (adapted from Sveiby, 2007)

\section{Results and Discussion}

The reliance on experience than on standard codified operating procedures is identified as the key aspect for the supervisors in the decision-making process. This is reflected in the tacit knowledge scores. As stated by one of the supervisors, “...how to do a layout...they don't teach in class”, while 
another asserted "...I am not a bookish kind of a guy and I never was...I used repetitions...learned from experience". According to the journeyman and the apprentice, on the job training and pairing with the experienced supervisors result in better learning than following written instructions. The results show that the average score of the supervisors with more than 25 years of experience is higher than the journeyman with 10-15 years of experience and an apprentice with less than 5 years of working experience (Figure 2). Although the sample size is not large enough to generalize, researchers are aiming to draw a relation between the experience of an individual and tacit knowledge score in the near future.

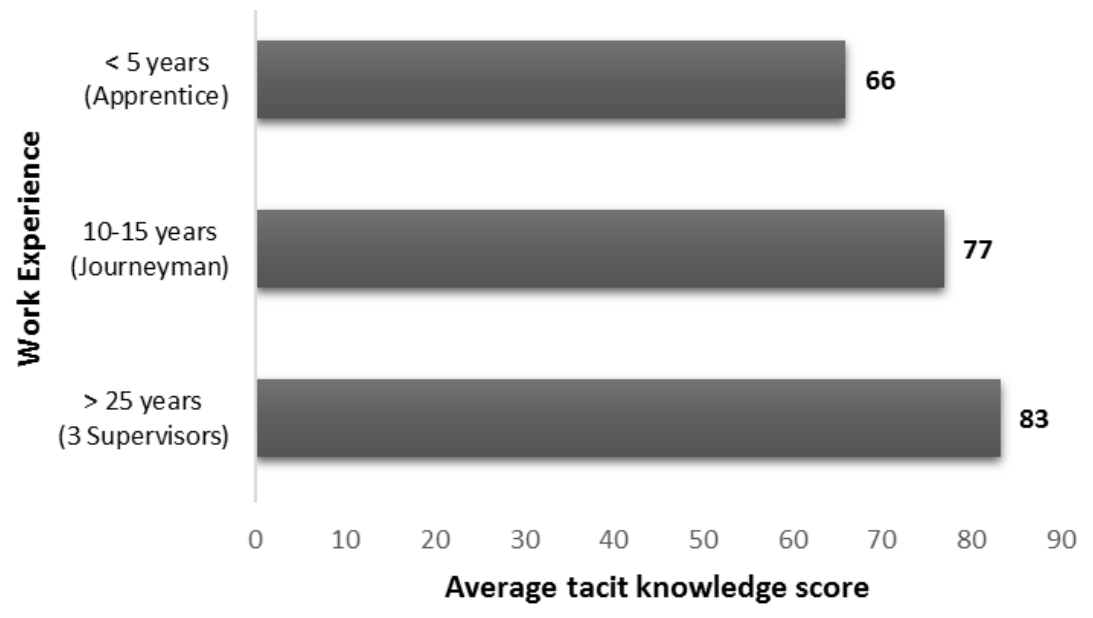

Figure 2: Validation results for the proposed measure (Qualitative, $N=5$ )

A total of 54 respondents completed the survey related to identifying barriers to knowledge sharing across the three contexts (Figure 3). Based on the rankings, for the group of workers context, 'lack of formal procedures to knowledge sharing' (B) is identified as the key barrier; for supervisor/manager behavior context, 'managers are resistant to change' (B) is identified as the key barrier; and for the organization as a whole, 'lack of formal procedures, (C) is identified as the key barrier to knowledge sharing. Personality interference, personal conflicts and grudges, poor communication, lack of confidence, job security, lack of formal sharing groups, and unwillingness to learn are some of the other responses obtained through free text entry options. These responses from the management and field personnel are compared to check the similarities and dissimilarities in the opinions. Perspectives of the field supervisors were different than the managers. According to field supervisors, managers and the field team are generally treated differently however, the responses from managers and executives are completely disparate. For them, managers and field staff are alike and do not impact the knowledge sharing process. 


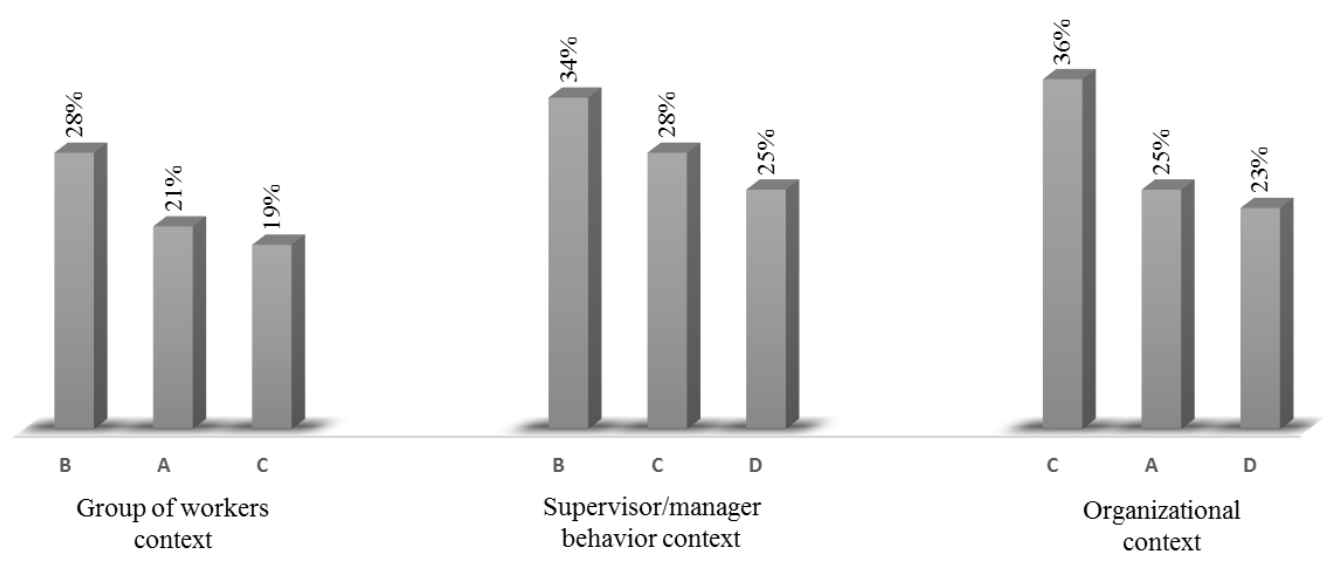

Figure 3: Barriers to Knowledge Sharing $(N=54)$

The instrument could be deployed by construction firms to identify the type of knowledge on which an individual is relying while performing a particular task. Conversely, tacit or explicit knowledge dependent construction activities could be identified. By doing so, organizations can act beforehand to capture the tacit knowledge of the experts and making it explicit to prepare the future workforce. Organizations can also incorporate this measure to check the effectiveness of apprenticeship training provided at the Jobsite. Field team perspectives are often ignored when the top management decides policies and strategies related to training and knowledge management. Organizations must consider the opinions of both sides to identify the potential barriers in knowledge sharing to strengthen the existing knowledge capturing strategies.

\section{Limitations and Future Research}

This is ongoing research and the results presented are tentative. The researchers are aiming to perform statistical analysis to validate the results after completing data collection which is one limitation to this study. Factor analysis will be performed to generate the final model and instrument for future researchers. Another limitation is that only electrical contractors were targeted which could impact the generalizability of the final results. The researchers are also aiming to discuss several methods to harness tacit knowledge of the experienced field supervisors to enhance the skill set of the workforce. Some of the identified methods for sharing know-hows are mentoring, storytelling, exit interviews, last lectures, and mixed reality.

\section{Acknowledgements}

The authors would like to express their deepest gratitude to ELECTRI International for funding this research and several National Electrical Contractors Association (NECA) chapters for their support. 


\section{References}

Ahmad, H. S., \& An, M. (2008). Knowledge management implementation in construction projects: a KM model for Knowledge Creation, Collection and Updating (KCCU). International Journal of Project Organization and Management, 11(2), 133-166. doi:10.1504/IJPOM.2008.022189

Anwar, R., Rehman, M., Wang, K., \& Hashmani, M. (2019). Systematic Literature Review of Knowledge Sharing Barriers and Facilitators in Global Software Developement Organizations Using Concept Maps. IEEE Access, (pp. 24231-24247).

Baker, M., Baker, M., Throne, j., \& Dutnell, M. (1997). Leveraging Human Capital. The Journal of Knowledge Management, 1(1), 63-74.

Bolisani, E., \& Bratianu, C. (2018). The Elusive Definition of Knowledge. In Emergent Knowledge Strategies: Strategic thinking in knowledge management (Vol. 4, pp. 1-22). Springer, Cham. doi:10.1007/978-3-319-60656_1

Chilton, M. A., \& Bloodgood, J. M. (2008). The Dimensions of Tacit \& Explicit Knowledge: A Description and Measure. International Journal of Knowledge Management, 4(2), 75-91. doi:10.1109/HICSS.2007.524

Deutskens, E., Ruyter, K. D., Wetzels, M., \& Oosterveld, P. (2004). Response rate and response quality of internet-based surveys: An experimental study. Marketing letters, 15(1), 21-36.

Dowell, B. E., \& Wexley, K. N. (1978). Development of a Work Behavior Taxonomy for First-Line Supervisors. Journal of Applied Psychology, 63(5), 563-572.

Egbu, C. O., \& Robinson, H. S. (2005). Construction as a Knowledge-Based Industry. In C. J. Anumba, C. Egbu, \& P. Carrillo, Knowledge Management in Construction (pp. 31-49). Blackwell Publishing .

Grover, R., \& Froese, T. M. (2016). Knowledge Management in Construction using a SocioBIM Platform: A Case Study of AYO Smart Home Project. Procedia Engineering, 145, 12831290. doi:10.1016/j.proeng.2016.04.165

Hedlund, J., Horvath, J., Forsythe, G., Snook, S., \& Williams, W. (1998). Tacit Knowledge in Military Leadership: Evedience of Construct Validity. Alexandria, Virginia: U.S. Army Research Institute for the Behavioural and Social Sciences.

Hunt, D. P. (2003). The concept of knowledge and how to measure it. Journal of Intellectual Capital, 4, 100-113. doi:10.1108/14691930310455414

Kivrak, S., Arslan, G., Dikmen, I., \& Birgonul, M. T. (2008). Capturing Knowledge in Construction Projects: Knowledge Platform for Contractors. Journal of Management in Engineering, 24(2), 87-95.

Leonard, N., \& Insch, G. S. (2010). Tacit Knowledge in Academia: A Proposed model and Measurement Scale. The Journal of Psychology, 139(6), 495-512. doi:10.3200/JRLP.139.6.495-512

MacNeil, C. M. (2004). Exploring the supervisor role as a facilitator of knowledge sharing in teams. Journal of European Induatrial Training, 28(1), 93-102. doi:10.1108/03090590410513901

Nesan, L. J. (2012). Factors Influencing Tacit Knowledge in Construction. Australian Journal of Construction Economics and Building, 5(1), 48-57.

Nonaka, I., \& Takeuchi, H. (1995). The Knowledge-Creating Company. New York: Oxford University Press, Inc.

Norberg-Johnson, D. (2019, 12 3). Preventing a Brain Drain: Retirement and Your Workforce | Electrical Contractor Magazine. Retrieved from Electrical Contractor Magazine: https://www.ecmag.com/section/your-business/preventing-brain-drain-retirement-and-yourworkforce 
Pathirage, C. P., Amaratunga, D. G., \& Haigh, R. P. (2007). Tacit knowledge and organizational performance: construction industry perspective. Journal of Knowledge Management, 11(1), 115-126.

Polanyi, M. (1966). The Tacit Dimension. Garden City, NY: Doubleday and Company, INC.

Skinnarland, S., \& Yndesdal, S. (2014). Barriers to a continuous learning process in construction. 22nd Annual Conference of International Group for Lean Construction, (pp. 1191-1201). Oslo, Norway.

Sveiby, K. E. (2007). Disabling the context for knowledge work: the role of managers' behaviours. Management Decision, 45(10), 1636-1655. doi:10.1108/00251740710838004

Teerajetgul, W., \& Chareonngam, C. (2008). Tacit knowledge utilization in Thai construction projects. Journal of Knowledge Management, 12(1), 164-174. doi:10.1108/13673270810852467

USAID. (2013). Tacit Knowledge: Knowledge Management Briefs. Retrieved from https://usaidlearninglab.org/sites/default/files/resource/files/ppl_guidance_docs_tacit_knowle dge_final.pdf

Wilkinson, R., Sherratt, F., \& Farrell, P. (2015). Knowledge management on site: a case study project. Proceedings of the Institution of Civil Engineers - Management, Procurement and Law, 168(2), 99-109.

\section{Appendix}

The following measure is implemented in the study:

Drag the "slider" along the line that conforms to your opinion regarding each item. Here is an example scenario based on the conversation with one of the field supervisors: "During estimation, I always spot opportunities to run conduit underground to save on costs."

\section{Now you have talked about this scenario, to what extent....}

1. Did you rely on written procedures?

Completely +------------------------------------------+Not at all

2. Did you rely on the construction documents provided?

Completely +------------------------------------------+Not at all

3. Did you rely on the knowledge gained from outside this project?

Completely +-----------------------------------------+Not at all

4. Could the knowledge you used be written down?

Completely +----------------------------------------+Not at all

5 . Would you have difficulty in explaining the procedures?

Completely +-------------------------------------------+Not at all

6 . Would viewing the final product allow you to understand the procedures involved?

Completely +-----------------------------------------+Not at all

7. Were you conscious of the procedures required?

Completely +----------------------------------------+Not at all

8. Did you utilize formal procedures?

Completely +--------------------------------------------+Not at all

9. Did you organize the procedures you used?

Completely +--------------------------------------------+Not at all

10. Did you rely on what you have learned from your past experience? 
Completely +---------------------------------------+Not at all

11. Could the procedures be written down so that anyone could follow them?

Completely +--------------------------------------+Not at all

12. Could you explain those procedures so that anyone could follow them?

Completely +------------------------------------+Not at all

13. Did the solutions come to you in a logical sequence?

Completely +------------ot at all

14. Would you have difficulty writing down the procedures you used?

Completely +---------------------------+Not at all

15. Would it be easier to demonstrate than telling others?

Completely +-----------------------------------+Not at all

16. Did you feel you knew how to do this without thinking about it?

Completely +-----------------ot at all

17. Did your actions seem instinctive instead of reasoned?

Completely +---------------------------------+Not at all

18. Were you already familiar with how to do this?

Completely +---------------------------------+Not at all

19. Did you spend more time planning the necessary steps or doing them?

Completely +------------------------------------+Not at all

20. Were you able to do this without thinking about it?

Completely +-----------------------------------+Not at all

21. Did you feel that you were repeating certain procedures?

Completely +-----------------------------------+Not at all

22. Did you have to invent new processes or procedures?

Completely +-----------------------------------+Not at all

23. Are you clear about your success on your finished project?

Completely +---------------------------------+Not at all

24. Could you explain why you did better or worse on this job than others?

Completely +----------------------------------+Not at all

25. Did you rely on your intuition?

Completely + Not at all

26. Did you change your typical approach to solving problems?

Completely +----------------------------------+Not at all

Note: Each of these questions was represented in the form of a semantic differential scale with "completely" and "not at all" representing the two extremities. Scores (1 to 5) were assigned corresponding to the position of the slider. Hence, the total score ranges from 130 (complete reliance on tacit knowledge) to 26 (complete reliance on explicit knowledge). Questions 3, 5, 6, 10, 14,15,16, 17, 18, 20, 21 and 25 were scored reverse i.e. 5 to 1 based on the model used for the study. 